\title{
Políticas Públicas y Transferencias Directas en América latina y el Caribe: Caracterización de los Beneficiarios del Programa Jefes de Hogar en Argentina
}

\author{
Marianela Sarabia ${ }^{(*)}$
}

\begin{abstract}
Resumen: Una de las facetas menos favorables de la globalización se ha manifestado en la desigual distribución de ingresos, activos y oportunidades. Con el afán reducir riesgos sociales como la pobreza y diseñar estrategias integrales de desarrollo surgieron los programas de transferencias directas. En un contexto favorable para América Latina y el Caribe se presentan algunos casos exitosos de estos programas con el propósito de delinear un marco de análisis para la experiencia de Argentina. Posteriormente, se estudia el Programa Jefes de Hogar en dos etapas. En primer lugar, se muestra la revisión de documentos, información e investigaciones. En segundo lugar, se aplican técnicas multivariantes de análisis de datos para observar las regularidades más significativas que se presentan entre sus beneficiarios a partir de la Encuesta Permanente de Hogares. Finalmente se exponen algunas observaciones a tener en cuenta en el diseño, la implantación y el seguimiento de estos programas.
\end{abstract}

Palabras-clave: Programas de Transferencias Directas, Ingresos, Pobreza, Argentina, América Latina, Políticas Públicas, Encuesta de Hogares, Análisis Multivariante, Programa Jefes de Hogar.

\begin{abstract}
One of the least favorable aspects of globalization has been shown by the uneven distribution of incomes, assets and opportunities. The conditional cash transfer programs were created with the aim of reducing social risks such as poverty and of designing comprehensive development strategies. Within a favorable context for Latin America and the Caribbean, some successful cases of these programs are introduced with the purpose of setting an analysis framework for the experience in Argentina.
\end{abstract}

Subsequently, an analysis of the Jefes de Hogar program is carried out in two stages. First, a revision of documents, data and researches on the matter is shown. Then, multivariate data analysis techniques are applied to observe the most significant regularities which appear among the program's beneficiaries as from the Encuesta Permanente de Hogares (Permanent Household Survey). Lastly, some remarks to be taken into account on the design, the implementation and the monitoring of the programs are shown.

Keywords: Cash Conditional Transfer, Income, Poverty, Argentina, Latin America, Public Policies, Household Survey, Multivariate Data Analysis, Jefes de Hogar Program.

(*) Economista por la Universidad de Buenos Aires. Dirección de Estudios y Coordinación Macroeconómicos, Subsecretaría de Programación Técnica y Estudios Laborales, Ministerio de Trabajo, Empleo y Seguridad Social de la República Argentina. E-mail: marianela.sarabia@gmail.com. Una primera versión del trabajo fue presentada en la Escuela de Verano sobre Economías Latinoamericana de la CEPAL en 2008. Se agradecen los valiosos comentarios de Paula Vijoditz y Soledad Villafañe en versiones preliminares. Recebido em 20.8.09 e aceito em 30.10.09. 


\section{INTRODUCCIÓN}

A mediados del siglo pasado, el Estado era el principal articulador de las dimensiones sociales y económicas, proveedor de servicios básicos como salud, educación, seguridad social o de empleos. Sin embargo, factores basados en la ineficiencia de la administración pública, el clientelismo político, sesgos en la distribución de recursos, desajuste fiscal y fragilidad institucional entre otros condujeron a implementar medidas completamente opuestas. El Estado debió relegar sus funciones frente al mercado y la eficiencia económica.

Durante el último cuarto del siglo XX, América latina mostró fuertes retrocesos en los indicadores sociolaborales mientras los indicadores económicos fueron erráticos aunque alentadores. Los primeros indicios de apertura y liberalización en los setenta, el impacto de la década perdida en los ochenta y el proceso de "reformas estructurales" sobredimensionaron la vulnerabilidad externa y las consecuencias negativas para gran parte de su población. La volatilidad y la exposición mundial durante los noventa hicieron evidente un problema fundamental de la economía global: la enorme asimetría entre un sistema financiero cada vez más sofisticado, dinámico e inestable y la ausencia de un marco institucional apropiado para regularlo (OCAMPO, 2000). Esto afectó tanto a países desarrollados como en desarrollo mientras la inequidad presente en el mundo entero aún refleja disparidades de la estructura económica y social.

En la región, la incidencia de la pobreza disminuyó aunque la cantidad de personas pobres aumentó significativamente y las brechas de calidad en la prestación de servicios básicos se incrementaron tanto como las brechas de ingresos. En tanto, bajo el precepto de la eficiencia, la flexibilización laboral implicó que el trabajo opere en un mercado con dinámicas similares al de productos sin tener en cuenta la repercusión social ni la desintegración del tejido productivo. Una de las dimensiones menos favorables de la globalización se ha manifestado en la desigual distribución de ingresos, activos y oportunidades. Durante los años ochenta, la desigualdad creció en 8 de 11 países latinoamericanos. En los noventa, creció en 10 y se estancó en 7 y durante estos últimos años descendió en 11 de 18 (CORNIA, 2008).

A comienzos del siglo XXI los indicadores macroeconómicos, los del mercado de trabajo, la pobreza y la desigualdad presentaron mejoras en la región al mismo tiempo que se coordinaron esfuerzos para impulsar el fortalecimiento institucional. En la actualidad, América latina está presenciando un cambio del signo político de sus gobiernos, luego de la rápida, profunda y desintegradora experiencia de las políticas neoliberales que sucedió a los casi cincuenta años de un "cuasi Estado de bienestar" latinoamericano (NOVICK, VILLAFAÑE, 2008).

Revertir los daños y encontrar soluciones para estas problemáticas vigentes aún es una tarea pendiente. Esto se convalida con los sucesos internacionales que desataron la crisis en 2008: primero el incremento del precio de los alimentos y los productos básicos, luego el colapso financiero en Estados Unidos. La crisis generada en el núcleo del sistema capitalista ahora reconoce que la intervención pública y las políticas para estimular la demanda y el consumo son esenciales para menguar el impacto recesivo. 
En este contexto cabe preguntarse cómo combatir la inequidad, cómo garantizar la igualdad de oportunidades, en qué consiste la inclusión social. Al considerar que la inclusión social es una construcción política y semántica, para ser definida correctamente demanda reconsiderar la noción de sociedad. Theret (2008) señala que a través de la protección social, la sociedad se autoprotege contra su propia descomposición. Ante ello, se resalta la necesidad de integrar asistencia y seguridad social en un sistema de protección basado en estrategias preventivas, de mitigación y de crisis. Pues, mientras la primera apunta a erradicar activamente la pobreza y formar ámbitos de integración a través de la redistribución de recursos de carácter no contributivo, la segunda se encuentra tradicionalmente asociada al mercado de trabajo, y por lo tanto, predomina el carácter contributivo.

En consonancia con ello, surgieron los programas de transferencias directas ${ }^{(1)}$ con la ambición de reducir riesgos sociales ${ }^{(2)}$ mediante el diseño de estrategias integrales de desarrollo. Condujeron a una innovación en materia de políticas sociales y se enmarcaron en un enfoque que apunta a crear y fortalecer capacidades de la población además de brindar asistencia bajo diversos horizontes temporales. En el corto plazo, apuntan a reducir la incidencia de la pobreza por ingresos mientras en el mediano y en el largo plazo buscan incrementar las capacidades de la población, mostrando que la carencia de capacidades y de redes de acceso que permitan vivir dignamente y/o adaptarse a los cambios contribuyen con la vulnerabilidad e impiden romper con el círculo intergeneracional de la pobreza.

Cabe preguntarse cuán viables y sostenibles son estos programas en el largo plazo. Si los mecanismos de salida o de graduación son efectivos para sus beneficiarios. Si ellos quedan supeditados a los recursos financieros o al traspaso de programas. Si estos programas tienen carácter coyuntural o son permanentes. Si son un instrumento de política social o son la nueva tendencia de la política social. Si las evaluaciones son consistentes con los objetivos del programa. Si sólo los trabajadores registrados reciben asignaciones familiares y cobertura de salud. Si falta coordinación entre los actores y/o se carece de control. Si el monto de las transferencias es extremadamente bajo. Si tienen cobertura reducida o presentan una filtración amplia. Si los mecanismos de selección y focalización son los adecuados. O si se desarrolla bajo un proceso estático, cerrado para nuevos beneficiarios.

Esas inquietudes guían este estudio. Durante su desarrollo se buscará obtener alguna respuesta. Después de la introducción, se mencionan algunas experiencias de transferencias directas en América latina con el propósito de delinear el contexto para analizar el Programa Jefes de Hogar (PJH) implementado en la República Argentina. En primer lugar se expone una revisión de documentos, investigaciones e información y posteriormente se aplica un análisis multivariante para observar las regularidades más significativas de los beneficiarios del programa a partir de la Encuesta Permanente de Hogares (EPH). Para concluir, se presentan observaciones y recomendaciones para el diseño, la implantación y el seguimiento de estos programas.

(1) También son conocidas como programas de transferencias condicionadas o cash conditional transfers.

(2) Se hace referencia a cuestiones como desempleo, vejez, carencia de ingresos, salud, pobreza, trabajo infantil, vulnerabilidad, analfabetismo funcional, desnutrición, etc. tendiendo a realizar una gestión del riesgo bajo modalidades más solidarias que individuales. 


\section{Los programas de transferencias directas en América latina y el Caribe}

Los programas de transferencias directas han cobrado gran importancia durante la última década, especialmente con la implementación del Progresa en México, del Bolsa Escola en Brasil o del Programa de Asignaciones Familiares (PRAF) en Honduras. Estos programas sociales suelen brindar un monto de ingresos al hogar que cumple con los requisitos de elegibilidad apuntando a reducir la incidencia de la pobreza por insuficiencia de ingresos al mismo tiempo que busca resolver problemas sociales ligados a ella. Los beneficios suelen ser regulares - mensuales o bimestrales - y estar focalizados en los hogares pobres.

A diferencia de la coyuntura donde cada uno de estos programas fue implementado, el contexto regional ha presentado un desempeño favorable durante los últimos años. América latina parecería haber logrado reducir parte de su característica vulnerabilidad a las fluctuaciones económicas gracias al aumento de su solvencia fiscal, producto de incrementos de los ingresos públicos por sobre el ritmo de los gastos. Ello ha permitido dedicar mayores recursos a la inversión pública y al gasto social, además de posibilitar la acumulación de recursos y diseñar instrumentos que posibiliten una acción contracíclica para hacer frente al impacto de un escenario externo adverso como el actual (CEPAL, 2008).

Para 2008 se estimó un crecimiento promedio del producto de 4,6\% en la región que completaría el sexto año consecutivo de crecimiento y el quinto con una tasa de aumento del PIB por habitante superior al 3\%. Para encontrar un período similar en la historia económica regional habría que remontarse a fines de los sesenta, donde una expansión se prolongó por 7 años acompañada por una mejora de los términos del intercambio (CEPAL, 2008). Sin embargo, la crisis alimentaria, energética y financiera no pasó desapercibida dado que el crecimiento del producto se ha desacelerado respecto de años anteriores y la evolución desigual de los términos de intercambio ha dado señales en la cuenta corriente, la inflación aumentó por el incremento de precios de los productos básicos, depreciación del dólar estadounidense y exceso de liquidez internacional.

Esto revela que la inflación no es un fenómeno estrictamente monetario; sino el resultado de desequilibrios de carácter real. Las presiones inflacionistas podrían tener su origen en desequilibrios de crecimiento situados en el comercio exterior y la agricultura; mientras que los mecanismos de propagación generalmente se reducirían al fiscal, el del crédito y el de reajuste de precios e ingresos (NOYOLA VÁSQUEZ, 1957). En tanto, la inflación no sería tan preocupante por el aumento de los precios en sí como por su impacto sobre la distribución del ingreso y las distorsiones que origina entre la estructura productiva y la estructura de la demanda. Emplear diferentes instrumentos de política económica coordinados con los de otras dimensiones resulta imprescindible para combatirla; pero como punto de partida es ineludible reconocerla.

Los indicadores laborales habían mejorado significativamente: la tasa de desocupación estimada en $7,5 \%$ superaba los tres puntos por debajo de la tasa observada a comienzos de la década (CEPAL, 2008). Además, el aumento del empleo era impulsado por puestos de trabajo asalariados que, al estar más asociados a puestos formales, indicarían una mejora de la calidad del empleo, en la pobreza y en la distribución del ingreso. En países 
como Argentina, esa dinámica se ve modificada por la coyuntura internacional dado que hubo una reducción leve del empleo que osciló tasas mensuales inferiores al 1\% entre noviembre y diciembre de 2008. En general se observa una merma en las incorporaciones más que aumentos en las desvinculaciones. En otras palabras, los esfuerzos orientados a evitar la destrucción de empleos han desplegado procedimientos preventivos de crisis, negociaciones colectivas e incentivos para mantener la nómina de asalariados. Por otro lado, la creación de empleo podría haber estado encabezada por puestos no registrados.

Los pronósticos para este año cambian según la institución que los anuncia. El FMI informó un retroceso del 1,6\% para el nivel de actividad de la región mientras el Banco Mundial comunicó una contracción del 0,6\% y la CEPAL auguraba un crecimiento de 1,9\%. Más allá de esto, el impacto del colapso global aún no puede ser mensurado en todas sus dimensiones y el Estado ha vuelto a participar activamente con medidas expansivas. Disparadores externos y procesos locales se combinan en la reducción del nivel de actividad y de consumo, los incrementos de precios o mayor precariedad constituyéndose en una alarma ante la lucha contra la pobreza y la desigualdad de los ingresos. De hecho, esto contribuye a que la capacidad de compra de los hogares más pobres se contraiga más dado que sus ingresos pueden resultar insuficientes, y en términos generales destinan una mayor proporción de su ingreso para adquirir productos básicos. Esto envuelve a los beneficiarios de programas de transferencias directas, quienes usualmente no perciben montos indexados.

\section{EXPERIENCIAS EN LA REGIÓN}

Las transferencias directas se destinan a los hogares con mayor carencia de ingresos mientras buscan generar co-responsabilidades entre el beneficiario y el Estado. Por un lado, el titular del beneficio debe garantizar el cumplimiento de ciertas condicionalidades como la asistencia escolar, el calendario de vacunación, los controles médicos y nutricionales de los niños del hogar. Por otro, el Estado debe proveer los servicios adecuados para hacer posible dicho cumplimiento.

Con sutiles diferenciaciones, algunos programas vinculan los requisitos o condicionalidades a una contraprestación laboral o formativa como el Plan Trabajar o el PJH implementados en Argentina. Otros, en cambio, toman la forma de prestaciones universales como el Plan de Atención Nacional a la Emergencia Social (PANES) de Uruguay que se constituyó en la puerta de entrada a programas más amplios como el de ingreso ciudadano que además contempla áreas de empleo, equidad social, salud bucal y alfabetización de adultos. Estas menciones dejan en evidencia que las transferencias directas se han expandido por América latina y el Caribe ${ }^{(3)}$ con características propias conforme la heterogeneidad intrarregional, e incluso han alcanzado a otros países en desarrollo como India o Turquía.

Las transferencias monetarias apuntan a reducir la pobreza extrema desde una perspectiva multidimensional, en la mayoría de los casos, tomando como unidad el hogar

(3) Ver Villatoro (2008), FAO (2008), Rawling y Rubio (2003). 
con hijos menores y/o discapacitados. Conforme a ello, se establecen tres líneas primordiales de acción para cubrir necesidades vitales y sociales básicas: nutrición, salud y educación. Esto tiene lugar en los albores del tercer milenio, cuando las Naciones Unidas exhortaron a que todos los países del globo se comprometan con los Objetivos de Desarrollo del Milenio ${ }^{(4)}$ (ODM), articulando esfuerzos orientados a mejorar la calidad de vida de la población y a crear capital humano. Aunque la informalidad laboral y la desigualdad en la región son las mayores del planeta, lo concerniente al ámbito laboral y a la mejora en la distribución de ingresos y activos quedó relegado en esas metas. ${ }^{(5)}$

En el plano regional, estos programas convergen tanto en los ejes de los ODM como en los instrumentos de focalización, las relaciones entre los niveles de gobierno ${ }^{(6)}$, el financiamiento y los mecanismos de identificación de potenciales beneficiarios. Sin embargo presentan diferencias en el tiempo de permanencia, en los mecanismos de graduación y de acompañamiento o la titularidad del beneficio, entre otros. En tanto, se debate si la titularidad constituye el empoderamiento de la mujer o una sobrecarga de responsabilidades.

Al respecto, se puede considerar el programa mexicano Oportunidades como un caso exitoso de evaluación permanente que ha dado lugar a reformulaciones significativas para mejorar su eficacia y adecuarlo a las necesidades de la población a lo largo del tiempo. Actualmente es un ejemplo en materia de coordinación de políticas que apuntan a erradicar la pobreza extrema rural y urbana puesto que integra una red de servicios, no existen mecanismos de graduación y tiene una fortaleza particular en el modelo de acompañamiento e identificación de los beneficiarios. Su objetivo primordial reside en efectivizar la transmisión intergeneracional de capital humano para que las próximas generaciones no sean pobres. Esta experiencia reveló que la construcción de redes sociales y la creación de hábitos saludables tomando como eje el hogar han contribuido a mejorar los hábitos de consumo y la organización familiar.

Cabe mencionar que el Progresa - el precursor del Oportunidades - inicialmente gastaba US\$ 1,34 en costos administrativos por cada dólar transferido a los beneficiarios. Si bien los costos de implementación fueron altos, durante el tercer año completo de funcionamiento los gastos administrativos disminuyeron a 5 centavos de dólar por cada dólar gastado en transferencias. Los gastos administrativos tales como la identificación de los beneficiarios, el establecimiento de mecanismos para la entrega de la prestación, la supervisión y la evaluación son comunes a todos los programas de protección social e impactan positivamente en su eficacia (ADATO, HODDINOTT, 2007).

El Programa Bolsa Familia de Brasil creado como programa estructurante del Cadastro Único en 2003 a raíz de las experiencias descentralizadas del Bolsa Escola,

\footnotetext{
(4) Los ocho pilares básicos son: 1. erradicar la pobreza extrema y el hambre; 2 . alcanzar la educación universal; 3. promover la igualdad entre los géneros; 4. reducir la mortalidad infantil; 5. mejorar la salud materna; 6. combatir el VIH/SIDA; 7. promover la sostenibilidad del medio ambiente y 8 . fomentar la asociación mundial.

(5) Argentina incluyó un ODM adicional "promover el trabajo decente" para consolidar su desarrollo a través de políticas consistentes y centradas con el empleo.

(6) En Paraguay, el programa nacional tiene un factor distintivo del proceso de focalización: la validación de la lista de beneficiarios potenciales por el comité local de selección de beneficiarios, el cual está compuesto por representantes locales y es responsable de estudiar a los beneficiarios potenciales y aprobar su selección (VERAS SORAES et al, 2008).
} 
ejemplifica cómo este tipo de transferencias puede ser articulado con otros beneficios sociales. Sin embargo, considerándolo desde la perspectiva de derechos con la que fue concebido, cabe señalar que se excluye del beneficio a 2 millones de familias en riesgo de pobreza, mientras persisten problemas de focalización vinculados con la volatilidad de ingresos de los más pobres (SORAES, 2008).

La convergencia en la implementación de transferencias directas tuvo lugar en simultáneo con el debate acerca de la libertad de elegir de la población dado que la asistencia en especies no era suficientemente aprovechada. No obstante son un ingreso monetario de libre utilización, el hogar lo emplea como desea y eso no garantiza que sea destinado a mejorar la calidad de vida de sus miembros aunque sí contribuye a mejorar los indicadores que miden brechas de pobreza e indigencia. En el siguiente capítulo se profundiza la indagación sobre los programas de transferencias directas con un análisis sobre la experiencia argentina. Se describe el contexto que dio origen al PJH y luego se expone el análisis empírico como parte de procesos sociales, económicos y políticos.

\section{Argentina: el Programa Jefes de Hogar}

Desde mediados de los setenta, la economía argentina había manifestado alta volatilidad, creciente exposición y vulnerabilidad externa. Después de la crisis del tequila (1994-1995), el crecimiento del desempleo condujo a la implementación programas de empleo con financiamiento y supervisión del Banco Mundial. En línea con esto, el Plan Trabajar permitió cubrir 350.000 beneficiarios aunque no pudo ser considerado universal o semi-universal debido a que el patrón de los programas implementados en los noventa frecuentemente era definido por el principio de responsabilidad fiscal, enfrentando una fuerte restricción presupuestaria (KOSTZER, 2006).

El desempeño de los noventa tuvo logros llamativos como un elevado crecimiento del producto sin un correlato semejante en el ámbito laboral (ALTIMIR et al, 2002). La crisis desatada a fines de 2001 fue el resultado de un largo proceso de reformas económicas y desarticulación sociopolítica. Estuvo caracterizada por el fin de la convertibilidad del peso con el dólar, la caída del nivel de actividad, el aumento del tipo del cambio, el colapso institucional y un alza significativa del precio de alimentos y bienes básicos entre otros con un fuerte deterioro en términos de pobreza y distribución del ingreso.

En 2001, el PBI cerró con una caída de 4,4\% respecto del año anterior y en 2002 la contracción del nivel de actividad rondó el $11 \%$. Se produjo un brutal aumento del desempleo que afectó principalmente a los jefes y jefas de hogar. El desempleo abierto que en 1991 era de 8,6\%, en mayo de 2002 había trepado a 21,5\%. En el mismo período, el empleo no registrado había pasado de 25,2\% a 38\%. Entre 2001 y 2002 el desempleo creció 17\%, mientras que entre los jefes y jefas de hogar se incrementó un 37\% y los jefes varones fueron los más perjudicados. Si bien los salarios nominales se mantuvieron constantes, la canasta básica de alimentos para una familia tipo aumentó casi un 34\%. En octubre de 2002, más de la mitad de la población $(54,3 \%)$ era considerada pobre. La indigencia también creció, pasando de 3\% en octubre de 1991, a 13\% en octubre de 2001 y a $24,7 \%$ en mayo de 2002 (Golbert, 2007). 
Estos resultados manifestaron la necesidad de reactivar la economía y extender la política social. En respuesta a la emergencia, en abril de 2002, el Decreto 565/02 permitió extender el Programa Jefes de Hogar (PJH) con consenso de universalización por parte de la Mesa de Diálogo Argentino. En este contexto, el derecho familiar a la inclusión social fue tomado como eje central para aliviar la pobreza extrema, disminuir el alto desempleo y revertir la parálisis productiva. El presupuesto inicial fue de 731 millones de pesos, monto muy inferior a las necesidades de cobertura.

En 2003 se emplearon 3,7 millones de pesos, que representaban aproximadamente el 1\% del PIB, cuyo financiamiento provino del Tesoro Nacional y de un préstamo del Banco Internacional de Reconstrucción y Fomento (BIRF) ${ }^{(7)}$. Con esta asignación presupuestaria, el PJH se transformó en el programa de asistencia a los sectores de menores ingresos que ha contado con mayores recursos en la historia argentina ${ }^{(8)}$ (GOLBERT, 2007). La cobertura geográfica del programa tampoco tuvo precedentes alcanzando el 16\% de los hogares de la República Argentina, aunque en el nivel regional la diferencia era elevada. En provincias como Formosa, Chaco y Jujuy la cobertura llegó al $40 \%$ de los hogares (KOSTZER, 2006).

La legislación nacional procuró garantizar la protección integral de la familia y asegurar el acceso de los hijos menores a la educación formal tanto como propiciar la incorporación de los jefes o jefas de hogar desocupados a la educación o a la formación que coadyuven a su futura reinserción laboral. Los beneficiarios ${ }^{(9)}$ debían realizar tareas comunitarias, productivas o actividades de formación. En otras palabras, contribuyó al empleo de sus beneficiarios a través de la exigencia de una contraprestación, principalmente en servicios comunitarios o de proximidad como así también en la administración pública. El PJH tuvo un efecto positivo en las mediciones inmediatas a su implementación: bajó el desempleo sensiblemente (3,7 pp) en mayor proporción de lo que había subido la tasa de empleo y la tasa de actividad (2,5 y 0,1 pp respectivamente).

Si no hubiese existido el PJH o una transferencia equivalente, los niveles de pobreza y especialmente los de indigencia hubiesen sido aun más elevados ${ }^{(10)}$. En 2004, la pobreza hubiera alcanzado a casi la totalidad de los hogares $(96,3 \%)$ y la indigencia al $78 \%$. La prestación del PJH tuvo mayor impacto para el alivio de la indigencia que el de la pobreza. Esto se explica porque el ingreso de los hogares se encontraba más próximo al

(7) El préstamos de 600 millones de dólares estaba destinado a cubrir servicios de consultoría, equipos y útiles de oficina, bienes y servicios para subproyectos. El pago de las amortizaciones se estableció en el período de octubre a 2007 a abril de 2016. (8) El PJH tuvo 1.207.314 beneficiarios durante el segundo semestre de 2006, en mayo de 2003 alcanzó el máximo con 1.990.735. En abril de 2009 se otorgaron 452.315 prestaciones, de las cuales el 73,3\% correspondía a la participación femenina.

(9) Destinado a jefes/as de hogar con hijos de hasta 18 años de edad, o discapacitados de cualquier edad, y a hogares en los que la jefa de hogar o la cónyuge, concubina o cohabitante del jefe se encontrase embarazada, todos ellos desocupados y que residan en forma permanente en el país.

(10) En Argentina, la medición de la pobreza considera la insuficiencia de ingresos monetarios para adquirir una canasta básica total que abarca alimentos, servicios básicos, recreación, vivienda, vestimenta y transporte. Es una medida monetaria que representa los requerimientos mínimos para satisfacer un umbral de necesidades básicas y tiene en cuenta la distancia para alcanzar el valor de dicha canasta, representado como una línea normativa (línea de pobreza). Análogamente, la indigencia se mide como insuficiencia de ingresos para adquirir una canasta básica alimentaria, considera la línea de indigencia como punto de referencia. En ambos casos, los requerimientos se calculan según el sexo y la edad de cada uno de los miembros del hogar tomando como referencia una unidad denominada adulto equivalente. 
valor de la canasta básica de alimentos. En cambio si se compara el ingreso de los hogares con la canasta básica total, el indicador de pobreza no disminuye tanto (SSPTyEL, 2004).

Inicialmente, la suma de $\$ 150$ representaba tres cuartas partes del salario mínimo vital y móvil (SMVM) fijo en \$200 durante la convertibilidad. En el segundo semestre de $2006^{(11)}$ el PJH representaba poco más de un quinto del SMVM vigente en $\$ 800$; y en diciembre de 2008 no alcanzaba un octavo del SMVM vigente en $\$ 1240$. Al monto del PJH, se adicionaron tres sumas fijar por única vez: en 2003 fue equivalente a un tercio del monto total, en 2004 a la mitad y en 2008 a dos tercios. Este beneficio puede compatibilizarse con otros programas de transferencia monetaria cuyo monto sea inferior.

El PJH fue implementado por el Ministerio de Trabajo y tuvo una ejecución descentralizada en los municipios. Las políticas de descentralización del gasto suelen asociarse con la necesidad de hacerlo más eficiente, combinando la búsqueda de una mejor atención de los problemas locales con un menor costo fiscal. Es decir, cuánto más cerca de los beneficiarios se ubique su provisión, mejor será la asignación de recursos, ya que la definición del gasto tendrá en cuenta preferencias locales y su control por parte de la ciudadanía será directa y efectivo (CETRÁNGOLO et al, 2003). El monitoreo del PJH se llevaría a cabo a través de Consejos Consultivos Locales, Provinciales y uno Nacional de Administración, Ejecución y Control (CONAEyC) ${ }^{(12)}$ del Derecho Familiar de Inclusión Social. Sin embargo, durante los últimos años, estas instancias de control no han realizado sus actividades regulares ni se han implementado acciones suficientes para considerar las observaciones realizadas.

En 2004 se realizó la segunda evaluación del PJH mediante una encuesta de beneficiarios partiendo del supuesto que aquellos que permanecían en el programa eran los que presentaban mayores dificultades de reinserción. En línea con esto, la focalización adecuada y la cobertura extendida serían claves para el proceso de inclusión social que llevó a cabo la política pública durante los últimos años mediante políticas sociales, laborales y previsionales ${ }^{(13)}$. En tanto, el número de beneficiarios se redujo por varias razones: por incorporación al mercado de $\operatorname{trabajo}^{(14)}$, por traspaso de programas $^{(15)} \mathrm{y}$

(11) Último período con datos disponibles que presentan suficiente confiabilidad durante su recolección y procesamiento. Como en la mayoría de las encuestas de hogares, existe cierto consenso sobre subdeclaración de ingresos y subcaptación de ingresos extremos.

(12) El CONAEYC estaba integrado por tres representantes de cada uno de los siguientes sectores: organizaciones de empleadores; organizaciones sindicales de los trabajadores; organizaciones no gubernamentales; instituciones confesionales y representantes del Gobierno Nacional. Los integrantes del Consejo eran designados a propuesta de cada uno de los sectores involucrados con desempeño "ad-honorem".

(13) La cobertura del Sistema de Seguridad Social había presentado un sesgo bismarkiano dado por la cobertura vinculada con la historia laboral de los trabajadores formales. Durante 2005-2008 Argentina implementó políticas tendientes a ampliar la cobertura del sistema previsional-y alterar dicho sesgo- mediante moratorias y disminución de los requisitos previsionales pasando del $47 \%$ al 92,8\% de la cobertura de los adultos mayores (MTEySS).

(14) Durante 2006, la tasa de desempleo en Argentina volvió a ser de un dígito (8,7\% para el último trimestre de ese año). De las 2.075.200 bajas que tuvo el PJH hasta abril de 2009, el 37,91\% se debió a incorporaciones en el mercado de trabajo mientras el 29,81\% del total se incorporó al empleo registrado con aportes en la Seguridad Social.

(15) El Seguro de Capacitación y Empleo fue creado mediante el Decreto 1506/2004 para implementar un esquema de políticas activas de empleo que brinden apoyo a los trabajadores desocupados del PJH en la búsqueda de empleo, en la actualización de sus competencias laborales y en su inserción laboral. En abril de 2009, la adhesión de beneficiarios del PJH alcanzó el 5,1\% de los beneficiarios del PJH desvinculados. A la vez, se dio origen al Programa Familias por la Inclusión 
fiscalización o incumplimiento de los requisitos iniciales. Indagar sobre las características de los beneficiarios con el propósito de conocer el ámbito de influencia del PJH es fundamental. A continuación se presentan los resultados de un análisis multivariante realizado a los beneficiarios del PJH cubiertos por la EPH durante el segundo semestre de 2006.

Desde la implementación del PJH, Argentina ha sido partícipe de diversas transformaciones que permiten replantear las acciones llevadas a cabo. El programa sería aplicado mientras dure la emergencia ocupacional argentina, que por decreto terminaría el 31 de diciembre de 2002 aunque esa fecha se pospuso anualmente ${ }^{(16)} \mathrm{y}$ en términos de incorporación de beneficiarios, permaneció cerrado. Los instrumentos de seguimiento y evaluación de beneficiarios serían fundamentales para medir su impacto y para rediseñar las estrategias iniciales con el propósito de aumentar su eficacia, tanto en términos de adecuar las demandas a nuevas necesidades u objetivos como para emplear eficientemente los recursos disponibles. Mientras se formuló la primera evaluación del PJH, en 2002 se aplicó un módulo especial del PJH para todos los aglomerados urbanos relevados por la EPH. Ese módulo permitía observar la situación frente al beneficio y las características de la contraprestación aunque soslayaba cuestiones relativas a la mejora en la calidad de vida de la población. Ese módulo sólo continuó siendo aplicado en tres aglomerados urbanos: Rawson-Trelew, San Nicolás-Constitución y Viedma-Carmen de Patagones.

\section{ANÁlisis MUlTiVARIANTE y RESUlTAdos}

Durante 2003 la EPH tuvo un cambio metodológico que incluyó una sección de tres preguntas para los beneficiarios del $\mathrm{PJH}$ en el cuestionario individual, discriminando si realizaban una contraprestación laboral tanto en su ocupación principal como en su ocupación secundaria o si no realizaban contraprestación. Consecuentemente, en este trabajo se optó por utilizar la base de hogares y personas para el segundo semestre de 2006. El universo de análisis ${ }^{(17)}$ se delimitó tanto por la titularidad del beneficio como por la no respuesta de los encuestados, independientemente de su condición de actividad. Poseer la titularidad del beneficio demanda ser mayor de 18 años de edad y tener hijos menores de hasta 18 años, hijos discapacitados o cónyuge embarazado. Se considera como ocupados a los beneficiarios que realizan una contraprestación laboral, entre los que no realizan contraprestación se encuentran los desocupados y los inactivos.

\footnotetext{
Social para proteger e integrar a las familias en riesgo social, a través de un ingreso no remunerativo y de actividades de promoción familiar y comunitaria. Busca transferir a beneficiarios del PJH en función de su vulnerabilidad y hasta 2008 se encontraba cerrado a nuevos beneficiarios. En 2005 tuvo 240.000, en 2006 tuvo 389.000 y en 2007 tuvo 539.386 familias beneficiarias. En abril de 2009, el traspaso de beneficiarios representó el 18,63\% de las desvinculaciones. En tanto, las bajas por fiscalización, incumplimiento de los requisitos u otras irregularidades rondaron el $26,5 \%$.

(16) Por la Ley № 25.561 se declaró la emergencia pública en materia social, económica, administrativa, financiera y cambiaria, y sus sucesivas leyes modificatorias prorrogaron sus efectos hasta el 31 de diciembre de 2009.

(17) Se emplearon 14 variables activas correspondientes a decil del ingreso total familiar, región, cocina, cantidad de menores de 10 años, sexo, lugar nacimiento, posición en el hogar, antigüedad laboral, actividad, categoría ocupacional o de inactividad, intensidad laboral, nivel educativo, cobertura médica, condición de pobreza del hogar con 56 categorías (dicotómicas o categóricas) asociadas. El tamaño de muestra consideró 729 casos mientras el tamaño de muestra ponderado con corrección por no respuesta de ingresos representó 161.573 casos. La EPH relevada por el INDEC se basa en una muestra probabilística estratificada en dos etapas de selección que desde ese momento alcanza a 31 aglomerados urbanos de la República Argentina.
} 
Para indagar sobre las características de los beneficiarios del PJH, se emplearon técnicas multivariantes de análisis de datos ${ }^{(18)}$ : se aplicó un análisis de correspondencias múltiples $^{(19)}(\mathrm{ACM})$ con el objetivo de obtener la representación gráfica de todas las categorías de las variables en un plano factorial. El ACM permite obtener una gran cantidad de factores que resume la información o inercia total que conforman los planos factoriales.

Las categorías más relevantes de las variables en la conformación del plano factorial seleccionado se identifican por ser aquellas que realizan una mayor contribución. De ese modo, en la conformación del primer eje factorial (horizontal en el gráfico 1) se destacan las variables relativas a la actividad laboral de los beneficiarios y a la región en donde éstos se desempeñan, de allí su denominación: caracterización de la actividad de beneficiarios del PJH (cuadro 1).

\section{Cuadro 1 - Categorías relevantes en la conformación del primer eje factorial (horizontal)}

\begin{tabular}{|c|c|}
\hline CONTRIBUCIONES NEGATIVAS & CONTRIBUCIONES POSITIVAS \\
\hline $\mathrm{NOA}$ & Región Pampeana \\
\hline De 1 a 5 años de antigüedad laboral & Sin computar antigüedad laboral \\
\hline Asalariado & Ama de casa \\
\hline Ocupado pleno & Sin computar intensidad laboral \\
\hline Administración pública & Inactivo \\
\hline Servicios sociales & \\
\hline
\end{tabular}

FUENTE: elaboración propia sobre la base de la EPH, 2ํㅗ semestre de 2006.

A primera vista se logra percibir que en el segmento negativo del primer eje se ubican los beneficiarios que residen en la región del NOA (noroeste argentino), con una antigüedad laboral de entre 1 y 5 años, lo cual permite asociar que el PJH podría haber sido un nexo entre el desempleo y el empleo al realizar una contraprestación laboral principalmente asociada con la administración pública y los servicios sociales. Dichas contraprestaciones representarían una jornada de entre 4 y 6 horas; consecuentemente, se podría plantear la idea de complementariedad con un empleo informal para concebir la noción de asalariado con una jornada horaria plena.

\footnotetext{
(18) Para comprender la metodología y los pasos seguidos en este análisis se recomienda ver Bécue, Valls i Marsal (2000), Everitt y Dunn (1991).

(19) En el ACM, la inercia total es una medida similar a la variación total en el caso de las componentes principales y mide el grado total de dependencia existente entre las variables. A partir de ella se calculan las proporciones de inercia explicada por cada una de las dimensiones a la hora de explicar las dependencias observadas así como las proporciones de inercia acumulada explicada por las dimensiones bajo análisis (SALVADOR, 2003). En este caso, las primeras dos dimensiones forman el plano factorial con un porcentaje acumulado del 14,55 de la inercia total, como los valores son relativamente bajos comparándolos con otras técnicas similares, el problema estrictamente teórico radica en qué factores seleccionar puesto que todos concentran información relevante.
} 
Las condiciones de pobreza de los hogares de los beneficiarios determinan que sus miembros desarrollen múltiples estrategias para la obtención y la generación de ingresos. Los beneficiarios, además de su participación en el PJH, se encontraban buscando trabajo y en muchos casos desarrollando actividades laborales caracterizadas por su precariedad, intermitencia e informalidad (changas, trabajos de corta duración, recolección de cartones y envases, remoción de escombros, etc.). Se encontraban también predispuestos a mejorar sus condiciones de empleabilidad, sea a través de la finalización de sus estudios formales y/o la capacitación laboral (SSPTyEL, 2004).

En tanto, el otro extremo se caracteriza por beneficiarios de la región pampeana para los cuales no se computa antigüedad ni intensidad laboral. En cuanto a su condición la actividad están contemplados como inactivos, involucra especialmente a las amas de casa, lo cual podría manifestar algún problema de focalización, la distribución de responsabilidades domésticas en el ámbito de la familia y/o la ausencia de servicios adecuados de apoyo al cuidado infantil que incluso dificultaría la inserción laboral femenina como señalaba Abramo (2005).

Por otro lado, el segundo eje factorial (vertical en el gráfico 1) reúne las categorías más relevantes de las variables relativas a las características socioeconómicas de los beneficiarios y de sus hogares, de allí su denominación: caracterización socioeconómica de beneficiarios del PJH (cuadro 2). En este caso, el segmento negativo del segundo eje factorial reúne a aquellos con mejor condiciones habitacionales dado que en el hogar cuentan con gas de red para cocinar, pertenecen al decil 6 en términos del ingreso total familiar (ITF), no tienen hijos menores de 10 años y el hogar se encuentra sobre la línea de pobreza para ese período. En cuanto a las características personales, principalmente se agrupan las mujeres, en condición de cónyuge, con alto nivel educativo y cobertura de salud. En consonancia con lo anterior, el hogar estaría en presencia de menores de entre 10 y 18 años.

\section{Cuadro 2 - Categorías relevantes en la conformación del segundo eje factorial (vertical)}

\begin{tabular}{|c|c|}
\hline CONTRIBUCIONES NEGATIVAS & CONTRIBUCIONES POSITIVAS \\
\hline Decil 6 & Decil 1 \\
\hline Con gas de red & Sin gas de red \\
\hline Sin menores de 10 años en el hogar & Hasta dos menores de 10 años en el hogar \\
\hline Mujer & Varón \\
\hline Nació en su actual provincia & Nació en otra provincia \\
\hline Cónyuge & Jefe \\
\hline Secundario completo o superior & Hasta primario incompleto \\
\hline Con cobertura de salud & Sin cobertura de salud \\
\hline Hogar no pobre & Hogar indigente \\
\hline
\end{tabular}

FUENTE: elaboración propia sobre la base de la EPH, 2ํㅗㄴ semestre de 2006. 
Para el segmento positivo, las mayores contribuciones en la conformación del segundo eje coinciden con los hogares más vulnerables puesto que hace referencia al primer decil del ITF y son indigentes, no poseen red de gas y cuentan con hasta dos menores de 10 años entre sus miembros. En cuanto a las características personales, los beneficiarios son varones con bajo nivel educativo o nulo que carecen cobertura de salud y responden a la condición de jefe de hogar. Incluso se encuentran asociados a migración interna dado que nacieron en una provincia diferente de su lugar de residencia.

Otra técnica multivariante empleada fue el análisis de clasificación jerárquica (ACJ), aplicado con posterioridad al ACM para agrupar a los beneficiarios a partir de sus respuestas en la encuesta. Este análisis permite establecer un conjunto de individuos con características similares ordenadas jerárquicamente según su proximidad en el plano factorial seleccionado. Proporciona una tipología de análisis de los beneficiarios respecto de sus características socioeconómicas, la organización del hogar y su vínculo con el mercado de trabajo conformando conglomerados indivisibles. Estos conjuntos que son objeto de estudio, presentan diferentes categorías de variables entendidas como características propias que brindan gran homogeneidad interna. En este sentido, la proporción de una modalidad en un conjunto es aproximadamente igual a la proporción de esa modalidad en el total de individuos encuestados (FERNÁNDEZ MACÍAS et al., 2004).

\section{Gráfico 1 - Beneficiarios del PJH: plano factorial con variables activas y grupos}

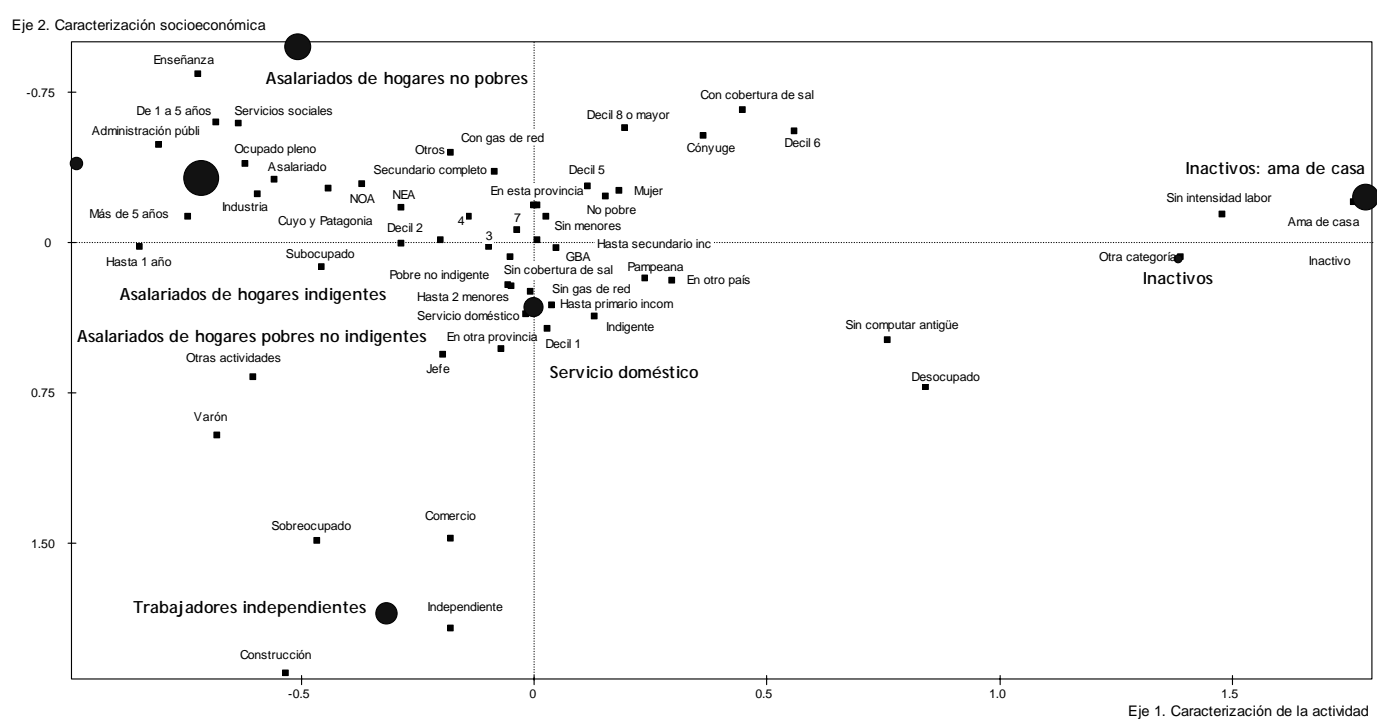

FUENTE: elaboración propia sobre la base de la EPH, ㅡㄴ semestre de 2006.

El criterio de significatividad viene dado por un valor test a partir de una distribución normal estandarizada que sirve para ordenarlas y trazar un perfil representativo. Cabe señalar que la forma de encadenar los análisis no es indiferente, puesto que se retroalimentan a la hora de brindar un panorama integral del fenómeno estudiado. En otras palabras, la utilización de estos métodos de trabajo muestra gran complementariedad y su aplicación de forma conjunta brinda buenos resultados en el análisis de 
encuestas (LEBART, 1994; WAISGRAIS, 2007). En la próxima sección se describen las clases obtenidas con la aplicación del ACJ, acompañándolas con un cuadro que presenta las categorías de las variables más relevantes para su conformación.

\section{Características de los grupos de beneficiarios del PJH}

\section{A) Asalariados de hogares POBRES}

Los asalariados de hogares pobres comprenden el 31,73\% de los beneficiarios del $\mathrm{PJH}$, denotándose como el grupo de mayor tamaño y gran vulnerabilidad. A la vez, se pueden dividir en dos subgrupos específicos según su condición frente a la indigencia:

Asalariados de hogares indigentes: (cuadro A1) engloba el 23,81\% de los beneficiarios constituyendo el núcleo de mayor dimensión y extrema vulnerabilidad. Los titulares del beneficio viven en hogares que pertenecen al primer decil del ITF y sus ingresos no fueron suficientes para cubrir la canasta básica alimentaria en el segundo semestre de 2006. Al advertir que su antigüedad laboral oscila de 1 a 5 años, sería factible creer que los miembros de este grupo se encontraban fuera del mercado de trabajo en el momento de incorporarse al programa. O en caso de pertenecer a la población económicamente activa por su antigüedad superior a los 5 años, implicaría que fueron desempleados u ocupados informales con ingresos de subsistencia con lo cual el PJH habría servido como nexo o puerta de acceso al empleo asalariado no registrado después de la crisis de 2001, principalmente en el sector de servicios sociales y personales. En cuanto a la intensidad laboral de la actividad, se desempeñan como subocupados horarios o tienen una jornada plena. Al analizar la problemática del desempleo en Argentina se observa que el mismo no se caracteriza por ser un fenómeno de larga duración. Por el contrario, la corta duración de los períodos de desocupación combinada con actividades intermitentes precarias, pondría en relieve la vinculación existente entre el desempleo, la precariedad laboral y los bajos salarios con el aumento de la pobreza. En esta dinámica, el desempleo constituye un momento particular recurrente de la vida laboral de las personas activas que se alterna con breves períodos de inserción en empleos precarios o de subsistencia. Empleos que, por otra parte, no constituyen fuentes de recalificación o recomposición de las competencias laborales requeridas por el mercado (SSPTyEL, 2004). Con respecto a la organización del hogar, los beneficiarios son jefes de hogares que en general carecen de cobertura de salud, poseen estudios primarios incompletos o nunca participaron de la educación formal. Se manifiesta migración interna dado que los beneficiarios nacieron en una provincia diferente de su lugar actual de residencia. 


\section{Cuadro Al - Asalariados de hogares indigentes.}

Efectivos: 38.473 - Porcentaje: 23,8

\begin{tabular}{|c|c|c|c|}
\hline VARIABLES & CATEgorías & $\begin{array}{l}\text { VALOR } \\
\text { TEST }\end{array}$ & Histograma \\
\hline Actividad & Servicios sociales & 196,67 & $\begin{array}{l}* * * * * * * * * * * * * * * * * * * * * * * * * * * * * \\
* * * * * * *\end{array}$ \\
\hline $\begin{array}{l}\text { Categoría ocupacional o de } \\
\text { inactividad }\end{array}$ & Asalariado & 194,30 & $\begin{array}{l}* * * * * * * * * * * * * * * * * * * * * * * * * * * * * * \\
* * * * * * *\end{array}$ \\
\hline Antigüedad laboral & De 1 a 5 años & 188,42 & $\begin{array}{l}* * * * * * * * * * * * * * * * * * * * * * * * * * * * * \\
* * * * * * *\end{array}$ \\
\hline Decil ingreso total familiar & Decil 1 & 103,26 & $\begin{array}{l}* * * * * * * * * * * * * * * * * * * * * * * * * * * * * \\
* * * * * * *\end{array}$ \\
\hline $\begin{array}{l}\text { Condición de pobreza del } \\
\text { hogar }\end{array}$ & Indigente & 92,83 & $\begin{array}{l}* * * * * * * * * * * * * * * * * * * * * * * * * * * * * * \\
* * * * * *\end{array}$ \\
\hline Antigüedad laboral & Más de 5 años & 84,32 & $\begin{array}{l}* * * * * * * * * * * * * * * * * * * * * * * * * * * * * \\
* * * *\end{array}$ \\
\hline Intensidad laboral & Subocupado & 76,75 & $* * * * * * * * * * * * * * * * * * * * * * * * * * * * *$ \\
\hline Intensidad laboral & Ocupado pleno & 72,13 & $* * * * * * * * * * * * * * * * * * * * * * * * * * * *$ \\
\hline
\end{tabular}

FUENTE: elaboración propia sobre la base de la EPH, 2ํㅗㄴ semestre de 2006.

\section{Cuadro A2 - Asalariados de hogares pobres no indigentes.}

Efectivos: 12.796 - Porcentaje: 7,92

\begin{tabular}{|c|c|c|c|}
\hline VARIABLES & CATEgorías & $\begin{array}{l}\text { VALOR } \\
\text { TEST }\end{array}$ & Histograma \\
\hline Actividad & $\begin{array}{l}\text { Administración } \\
\text { pública }\end{array}$ & 171,80 & $\begin{array}{l}* * * * * * * * * * * * * * * * * * * * * * * * * * * * * * \\
* * * * * * *\end{array}$ \\
\hline Decil ingreso total familiar & Decil 2 & 147,73 & $\begin{array}{l}* * * * * * * * * * * * * * * * * * * * * * * * * * * * * \\
* * * * * * *\end{array}$ \\
\hline Antigüedad laboral & Hasta 1 año & 129,42 & $\begin{array}{l}* * * * * * * * * * * * * * * * * * * * * * * * * * * * * \\
* * * * * * *\end{array}$ \\
\hline Posición en el hogar & Otros & 120,95 & $\begin{array}{l}* * * * * * * * * * * * * * * * * * * * * * * * * * * * * \\
* * * * * * *\end{array}$ \\
\hline $\begin{array}{l}\text { Categoría ocupacional o de } \\
\text { inactividad }\end{array}$ & Asalariado & 107,86 & $\begin{array}{l}* * * * * * * * * * * * * * * * * * * * * * * * * * * * * * \\
* * * * * * *\end{array}$ \\
\hline $\begin{array}{l}\text { Condición de pobreza del } \\
\text { hogar }\end{array}$ & Pobre no indigente & 104,21 & $\begin{array}{l}* * * * * * * * * * * * * * * * * * * * * * * * * * * * * * \\
* * * * * * *\end{array}$ \\
\hline Lugar nacimiento & En esta provincia & 71,46 & $* * * * * * * * * * * * * * * * * * * * * * * * * * * *$ \\
\hline Sexo & Varón & 68,53 & 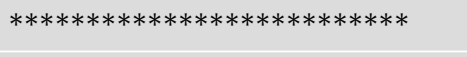 \\
\hline Intensidad laboral & Ocupado pleno & 63,90 & $* * * * * * * * * * * * * * * * * * * * * * * * *$ \\
\hline
\end{tabular}

FUENTE: elaboración propia sobre la base de la EPH, 2ํㅗ semestre de 2006. 
Asalariados de hogares pobres no indigentes: (cuadro A2) alcanza el 7,92\% de los beneficiarios, quienes viven en hogares que pertenecen al segundo decil del ITF, sus ingresos fueron suficientes para cubrir la canasta básica alimentaria pero no para cubrir la canasta básica total. En general, residen en el Gran Buenos Aires (GBA) y los hogares poseen 3 menores de 10 años o más. Frente al mercado de trabajo, los puestos asalariados de jornada plena que ocupan estos beneficiarios son muy nuevos dado que su antigüedad laboral es inferior al año y se encuentran principalmente asociados con la administración pública. Se diferencia del grupo anterior en cuanto a la antigüedad laboral, aunque no ocurre lo análogo con respecto a la vulnerabilidad del hogar. Esto conlleva a remarcar la vinculación entre los períodos de desempleo y empleo precario ya mencionada. Con relación a su posición en el hogar, no son clasificados como jefes ni como cónyuges, sino que integran la categoría de "otros" conformada en mayor medida por hijos (mayores de 18 años) o por otras relaciones de parentesco contribuyendo a desarrollar una estrategia de supervivencia para el hogar. En este caso se presenta un fuerte sesgo de género, ya que la categoría varón tiene gran relevancia. Nacieron en la misma provincia que viven y carecen de cobertura de salud.

\section{B) TRABAJADORES DE SECTORES DE ACTIVIDAD TRADICIONALMENTE ASOCIADOS A LA PRECARIEDAD}

Los trabajadores de los sectores de actividad tradicionalmente vulnerables representan el 27,88\% de los beneficiarios del PJH. Este conjunto presenta dos subgrupos específicos según características particulares que vinculan el sector de actividad y el género de los beneficiarios, dando lugar a trabajadores independientes asociados al comercio y la construcción por un lado; y al servicio doméstico por otro. Según datos de EPH para 2006, la cantidad de mujeres que desarrollaba sus actividades en la construcción se situaba en el 3\%, mientras que en transporte y comunicaciones alcanzaba el 15\%. Esto manifiesta que el sexo de los trabajadores incide significativamente en la composición de ciertas ramas de actividad. Por otro lado, el crecimiento de ambas ramas se encontraría vinculado al ciclo expansivo del producto y a la informalidad tradicional.

Del estudio del perfil ocupacional de los beneficiarios se desprende que una proporción importante de los mismos constituye un grupo con serias dificultades de inserción laboral. Las características de baja calificación, asociada además con servicio doméstico y construcción, los vinculan estrechamente con la problemática del empleo no registrado. Efectivamente, estudios realizados a partir de los datos de la EPH ponen en evidencia una elevada correlación entre la calificación de los trabajadores y la temática del empleo no registrado: a menor calificación, mayor incidencia de la no registración (SSPTyEL, 2004). A continuación se describen las dos tipologías:

Trabajadores independientes: (cuadro B1) abarca el 14,79\% de los beneficiarios que tiene características fuertemente asociadas a las ramas de actividad de construcción y comercio. Son trabajadores independientes que desempeñan una jornada laboral extendida por sobre los límites legales vigentes. Aunque no presenta una asociación fuerte con respecto al nivel de ingresos de su hogar, éstos podrían ser muy vulnerables y dejarlo en el límite de la indigencia. Más aún si se considera que desarrolla actividades de baja productividad, en condiciones de subsistencia o temporales. Son varones jefes de hogar, 
manifestando el sesgo de género asociado con las ramas mencionadas. Carecen de cobertura de salud y nacieron en una provincia diferente de su actual lugar de residencia, indicando movilidad interna. Sin embargo, la diferenciación socioeconómica resulta más relevante que la categoría ocupacional. Consistiendo los resultados con un estudio similar sobre informalidad laboral, se encuentra que un conjunto de trabajadores, asalariados e independientes, desarrolla sus actividades en la economía informal con extrema vulnerabilidad. Tal como fue analizado, en estos grupos predominan trabajadores varones, migrantes, sin cobertura de salud, con niveles educativos muy bajos, bajas calificaciones y necesidades básicas insatisfechas. Usualmente, las actividades son desarrolladas en sectores de comercio callejero, construcción y transporte (Waisgrais y Sarabia, 2008).

\section{Cuadro B1 — Trabajadores independientes. Efectivos: 23.890 - Porcentaje: 14,79}

\begin{tabular}{|c|c|c|c|}
\hline VARIABLES & CATEgorías & $\begin{array}{l}\text { VALOR } \\
\text { TEST }\end{array}$ & Histograma \\
\hline $\begin{array}{l}\text { Categoría ocupacional o de } \\
\text { inactividad }\end{array}$ & Independiente & 288,84 & $\begin{array}{l}* * * * * * * * * * * * * * * * * * * * * * * * * * * * * \\
* * * * * * *\end{array}$ \\
\hline Intensidad laboral & Sobreocupado & 166,47 & $\begin{array}{l}* * * * * * * * * * * * * * * * * * * * * * * * * * * * * \\
* * * * * * *\end{array}$ \\
\hline Actividad & Comercio & 164,91 & $\begin{array}{l}* * * * * * * * * * * * * * * * * * * * * * * * * * * * * * \\
* * * * * * *\end{array}$ \\
\hline Actividad & Construcción & 157,21 & $\begin{array}{l}* * * * * * * * * * * * * * * * * * * * * * * * * * * * * \\
* * * * * * *\end{array}$ \\
\hline Sexo & Varón & 150,09 & $\begin{array}{l}* * * * * * * * * * * * * * * * * * * * * * * * * * * * * \\
* * * * * * *\end{array}$ \\
\hline Posición en el hogar & Jefe & 116,79 & $\begin{array}{l}* * * * * * * * * * * * * * * * * * * * * * * * * * * * * \\
* * * * * * *\end{array}$ \\
\hline Antigüedad laboral & $\begin{array}{l}\text { Sin computar anti- } \\
\text { güedad }\end{array}$ & 109,55 & $\begin{array}{l}* * * * * * * * * * * * * * * * * * * * * * * * * * * * * * \\
* * * * * * *\end{array}$ \\
\hline
\end{tabular}

FUENTE: elaboración propia sobre la base de la EPH, 느s semestre de 2006.

\section{Cuadro B2 — Servicio doméstico. Efectivos: 21.147 — Porcentaje: 13,09}

\begin{tabular}{|c|c|c|c|}
\hline VARIABLES & CATEgorías & $\begin{array}{l}\text { VALOR } \\
\text { TEST }\end{array}$ & Histograma \\
\hline Actividad & Servicio doméstico & 289,44 & $\begin{array}{l}* * * * * * * * * * * * * * * * * * * * * * * * * * * * * \\
* * * * * * *\end{array}$ \\
\hline Antigüedad laboral & $\begin{array}{l}\text { Sin computar anti- } \\
\text { güedad }\end{array}$ & 161,84 & $\begin{array}{l}* * * * * * * * * * * * * * * * * * * * * * * * * * * * * * \\
* * * * * * *\end{array}$ \\
\hline $\begin{array}{l}\text { Categoría ocupacional o de } \\
\text { inactividad }\end{array}$ & Asalariado & 131,47 & $\begin{array}{l}* * * * * * * * * * * * * * * * * * * * * * * * * * * * * * \\
* * * * * * *\end{array}$ \\
\hline Intensidad laboral & Subocupado & 109,54 & $\begin{array}{l}* * * * * * * * * * * * * * * * * * * * * * * * * * * * * * \\
* * * * * * *\end{array}$ \\
\hline
\end{tabular}




\begin{tabular}{|l|l|l|l|}
\hline \multicolumn{1}{|c|}{ VARIAbles } & \multicolumn{1}{c|}{ CATEgorías } & $\begin{array}{c}\text { VALOR } \\
\text { TEST }\end{array}$ & \multicolumn{1}{c|}{ Histograma } \\
\hline Lugar nacimiento & En otro país & 69,95 & $* * * * * * * * * * * * * * * * * * * * * * * *$ \\
\hline Sexo & Mujer & 67,69 & $* * * * * * * * * * * * * * * * * * * * * * * *$ \\
\hline Cobertura médica & $\begin{array}{l}\text { Sin cobertura de } \\
\text { salud }\end{array}$ & 65,29 & $* * * * * * * * * * * * * * * * * * * * * * *$ \\
\hline Actividad & Desocupado & 64,77 & $* * * * * * * * * * * * * * * * * * * * * * *$ \\
\hline Decil ingreso total familiar & Decil 1 & 60,42 & $* * * * * * * * * * * * * * * * * * * * * *$ \\
\hline Posición en el hogar & Jefe & 56,61 & $* * * * * * * * * * * * * * * * * * * *$ \\
\hline
\end{tabular}

FUENTE: elaboración propia sobre la base de la EPH, 2ํㅡ semestre de 2006.

Servicio doméstico: (cuadro B2) comprende el 13,09\% de los beneficiarios cuyos hogares pertenecen al primer decil del ITF y refleja que son indigentes y vulnerables. Este grupo, principalmente integrado por mujeres jefas de hogar, también manifiesta el sesgo de género que estaría asociado a la rama de actividad. Las beneficiarias del programa están insertas en el mercado de trabajo dado que en su mayoría son trabajadoras asalariadas con una jornada laboral reducida en el servicio doméstico. En menor proporción también hay desocupadas. Carecen de cobertura de salud y nacieron en otro país, por lo cual se deduce que este campo más allá de pertenecer a la economía informal o sumergida, es un refugio para la migración externa. Un dato muy significativo que surgió de la segunda encuesta de beneficiarios es la alta proporción de beneficiarias mujeres que se encontraban a cargo de los hijos y no tenían cónyuge. Dicha situación, alcanzó al 60\% de las beneficiarias y podría explicar la alta participación de mujeres en el programa ${ }^{(20)}$. Estas familias monoparentales con jefatura femenina se ubican en los quintiles más bajos de ingresos, revelando una situación de mayor vulnerabilidad (ver SSPTyEL, 2004). En cuanto a las características de la rama, más de dos terceras partes trabajan menos de 35 horas semanales. Es importante señalar que entre ellas, más de la mitad busca trabajar más tiempo. La precariedad laboral caracteriza las condiciones en que se desarrolla esta ocupación. El 94,5\% del total de las empleadas del servicio doméstico - no sólo las beneficiarias del PJH - que trabajan 6 horas o más no tenía descuentos jubilatorios. El desarrollo de la actividad laboral en la vivienda del empleador es un factor importante, que condiciona la elevada precariedad laboral de las trabajadoras del servicio doméstico (Contartese et al, 2005). Según el Módulo de Informalidad de la EPH aplicado en el Gran Buenos Aires (2005), el 92\% de los asalariados en hogares son mujeres; de ellas, el 97\% son empleadas domésticas y el 94\% son empleadas domésticas informales.

\section{C) Asalariado de hogares no pobres}

Este grupo de asalariados representa el $17,81 \%$ de los beneficiarios del PJH y posee características poco compatibles con las de los beneficiarios de programas de asistencia social tradicional. No pertenecen a hogares pobres, en su mayoría integran el decil sép-

(20) En abril de 2008, la participación femenina en el programa representaba poco más del $73 \%$ los beneficiarios. 
timo y no presentan miembros menores de 10 años a cargo. Esto último podría ser causa del crecimiento habitual de los menores desde el alta del hogar en el programa y haber permitido mayor autonomía materna y reorganización familiar (cuadro C).

En materia laboral, son asalariados con ocupaciones plenas vinculadas con áreas de servicios sociales y enseñanza, con una antigüedad de entre 1 y 5 años, por lo cual se habrían insertado en un puesto de trabajo durante la recuperación económica con creación de empleo que tuvo lugar en los últimos años. Dicha inserción sería informal y permitiría mantener la titularidad del beneficio. Considerando las características personales y la posición en el hogar que tienen en el hogar, estos beneficiarios son cónyuges que poseen cobertura de salud y altos niveles educativos, ya sea secundario completo o superior.

Podrían plantearse más hipótesis sobre la dinámica de comportamiento al respecto. Probablemente, el comportamiento de los beneficiarios de esta clase haya tenido que ver más con una estrategia del hogar para superar la crisis que con una situación extrema de desempleo y pobreza. Podría suponerse que aun cuando el jefe de hogar tuviera un trabajo registrado en la seguridad social - y brindara cobertura de salud al grupo familiar o pudiera realizar aportes voluntarios -, el cónyuge habría optado por inscribirse como beneficiario del PJH.

Incluso, el planteo sobre si la asignación mensual del PJH per se podría generar incentivos perversos para insertarse en un puestos formales de trabajo (GASPARINI et al, 2006) no sería consistente para la mayoría de los casos. Para el último trimestre de 2006, se observaba que el salario promedio de los registrados fue de \$1.404 mientras el de los asalariados no registrados fue de $\$ 730$, éste sólo representaba la mitad del primero. Al considerar la suma del salario promedio de los no registrados y una transferencia directa - el PJH equivale a \$150 o el Plan Familias ronda \$305 en el caso de hogares con 6 o más hijos menores - no bastaría para compensar los ingresos promedios del empleo registrado.

\section{Cuadro C - Asalariados de hogares no pobres. \\ Efectivos: 28.775 - Porcentaje: 17,81}

\begin{tabular}{|c|c|c|c|}
\hline VARIABLES & Categorías & $\begin{array}{l}\text { VALOR } \\
\text { TEST }\end{array}$ & HistogRAMA \\
\hline $\begin{array}{l}\text { Condición de pobreza del } \\
\text { hogar }\end{array}$ & No pobre & 193,72 & $\begin{array}{l}* * * * * * * * * * * * * * * * * * * * * * * * * * * * * \\
* * * * * * *\end{array}$ \\
\hline Antigüedad laboral & De 1 a 5 años & 157,20 & $\begin{array}{l}* * * * * * * * * * * * * * * * * * * * * * * * * * * * * \\
* * * * * * *\end{array}$ \\
\hline $\begin{array}{l}\text { Categoría ocupacional o de } \\
\text { inactividad }\end{array}$ & Asalariado & 144,93 & $\begin{array}{l}* * * * * * * * * * * * * * * * * * * * * * * * * * * * * \\
* * * * * * *\end{array}$ \\
\hline Intensidad laboral & Ocupado pleno & 113,95 & $\begin{array}{l}* * * * * * * * * * * * * * * * * * * * * * * * * * * * * * \\
* * * * * * *\end{array}$ \\
\hline Cobertura médica & $\begin{array}{l}\text { Con cobertura de } \\
\text { salud }\end{array}$ & 102,87 & $\begin{array}{l}* * * * * * * * * * * * * * * * * * * * * * * * * * * * * \\
* * * * * * *\end{array}$ \\
\hline Posición en el hogar & Cónyuge & 101,94 & $\begin{array}{l}* * * * * * * * * * * * * * * * * * * * * * * * * * * * * \\
* * * * * * *\end{array}$ \\
\hline
\end{tabular}




\begin{tabular}{|c|c|c|c|}
\hline VARIABLES & CATEGorías & $\begin{array}{l}\text { VALOR } \\
\text { TEST }\end{array}$ & Histograma \\
\hline Actividad & Enseñanza & 96,30 & $\begin{array}{l}* * * * * * * * * * * * * * * * * * * * * * * * * * * * * \\
* * * * * * *\end{array}$ \\
\hline Actividad & Servicios sociales & 79,91 & ******************************** \\
\hline Nivel educativo & $\begin{array}{l}\text { Secundario com- } \\
\text { pleto }\end{array}$ & 76,15 & $* * * * * * * * * * * * * * * * * * * * * * * * * * * * * * *$ \\
\hline Decil ingreso total familiar & Decil 7 & 74,96 & $* * * * * * * * * * * * * * * * * * * * * * * * * * * * *$ \\
\hline
\end{tabular}

FUENTE: elaboración propia sobre la base de la EPH, 2을 semestre de 2006.

Por otro lado, la información provista por el Módulo de Informalidad refleja que la informalidad laboral sería una alternativa al desempleo para los trabajadores con características socioeconómicas vulnerables. En tanto, la Encuesta de Percepción de Planes Sociales ${ }^{(21)}$ manifiesta que hay una preferencia mayoritaria por prestaciones con beneficios tangibles en el mercado laboral, como la capacitación y el acceso a bolsas de trabajo, aún con menores beneficios monetarios de los planes.

\section{D) INACTIVOS}

Los inactivos alcanzan el 22,58\% de los beneficiarios relevados por la EPH puesto que no participaron del mercado laboral durante la semana de referencia para dicha medición. Ante ello no se les imputa intensidad ni antigüedad laboral. Por medio del ACJ se obtuvieron dos grupos dentro de esta categoría con similares características, uno abarca el 18,02\% de los beneficiarios y está integrado por amas de casa (cuadro D1) mientras el otro comprende el 4,56\% con beneficiarios inactivos en el mercado de trabajo.

Con respecto a las características del hogar, pertenecen a deciles medios o altos en términos de la distribución del ITF, entre sus miembros no se presentan más de dos menores de 10 años y poseen red de gas para cocinar — indicador que denota condiciones socioambientales favorables. Habitualmente son mujeres, que en la organización familiar desempeñan el rol de cónyuges y poseen cobertura de salud.

Cuadro D1 — Inactivos: amas de casa. Efectivo: 29.119 — Porcentaje: 18,02

\begin{tabular}{|l|l|l|l|}
\hline \multicolumn{1}{|c|}{ VARIABLES } & \multicolumn{1}{|c|}{ CATEGORÍAS } & $\begin{array}{c}\text { VALOR } \\
\text { TEST }\end{array}$ & \multicolumn{1}{c|}{ Histograma } \\
\hline $\begin{array}{l}\text { Categoría ocupacional o de } \\
\text { inactividad }\end{array}$ & Ama de casa & 378,81 & $\begin{array}{l}* * * * * * * * * * * * * * * * * * * * * * * * * * * * * \\
* * * * * *\end{array}$ \\
\hline Actividad & Inactivo & 348,24 & $\begin{array}{l}* * * * * * * * * * * * * * * * * * * * * * * * * * * * * \\
* * * * * * *\end{array}$ \\
\hline
\end{tabular}

(21) Presentación de los resultados de la Encuesta de Percepción de Planes Sociales en la Argentina a cargo de Cruces y Rovner (CEDLAS y Equipo Moori, 2007). 


\begin{tabular}{|c|c|c|c|}
\hline VARIABLES & Categorías & $\begin{array}{l}\text { VALOR } \\
\text { TEST }\end{array}$ & Histograma \\
\hline Intensidad laboral & $\begin{array}{l}\text { Sin intensidad la- } \\
\text { boral }\end{array}$ & 313,28 & $\begin{array}{l}* * * * * * * * * * * * * * * * * * * * * * * * * * * * * \\
* * * * * * *\end{array}$ \\
\hline Antigüedad laboral & $\begin{array}{l}\text { Sin computar anti- } \\
\text { güedad }\end{array}$ & 221,70 & $\begin{array}{l}* * * * * * * * * * * * * * * * * * * * * * * * * * * * * \\
* * * * * * *\end{array}$ \\
\hline Sexo & Mujer & 105,27 & $\begin{array}{l}* * * * * * * * * * * * * * * * * * * * * * * * * * * * * \\
* * * * * * *\end{array}$ \\
\hline Posición en el hogar & Cónyuge & 80,62 & $* * * * * * * * * * * * * * * * * * * * * * * * * * * * * * * *$ \\
\hline Decil ingreso total familiar & Decil 6 & 70,89 & $* * * * * * * * * * * * * * * * * * * * * * * * * * * *$ \\
\hline Cobertura médica & $\begin{array}{l}\text { Con cobertura de } \\
\text { salud }\end{array}$ & 50,44 & $* * * * * * * * * * * * * * * * * * * *$ \\
\hline
\end{tabular}

Fuente: elaboración propia sobre la base de la EPH, $2^{\circ}$ semestre de 2006.

\section{Cuadro D2 — Inactivos. Efectivos: 7.373 - Porcentaje: 4,56}

\begin{tabular}{|c|c|c|c|}
\hline VARIABLES & Categorías & $\begin{array}{l}\text { VALOR } \\
\text { TEST }\end{array}$ & Histograma \\
\hline $\begin{array}{l}\text { Categoría ocupacional o de } \\
\text { inactividad }\end{array}$ & Otra categoría & 231,92 & $\begin{array}{l}* * * * * * * * * * * * * * * * * * * * * * * * * * * * * \\
* * * * * * *\end{array}$ \\
\hline Antigüedad laboral & $\begin{array}{l}\text { Sin computar anti- } \\
\text { güedad }\end{array}$ & 105,18 & $\begin{array}{l}* * * * * * * * * * * * * * * * * * * * * * * * * * * * * * * \\
* * * * * * *\end{array}$ \\
\hline Intensidad laboral & $\begin{array}{l}\text { Sin intensidad la- } \\
\text { boral }\end{array}$ & 104,96 & $\begin{array}{l}* * * * * * * * * * * * * * * * * * * * * * * * * * * * * \\
* * * * * * *\end{array}$ \\
\hline Actividad & Inactivo & 91,91 & $\begin{array}{l}* * * * * * * * * * * * * * * * * * * * * * * * * * * * * \\
* * * * *\end{array}$ \\
\hline Decil ingreso total familiar & Decil 7 & 59,83 & $* * * * * * * * * * * * * * * * * * * * * *$ \\
\hline $\begin{array}{l}\text { Cantidad de menores de } 10 \\
\text { años }\end{array}$ & Hasta 2 menores & 58,44 & $* * * * * * * * * * * * * * * * * * * * * *$ \\
\hline Decil ingreso total familiar & Decil 5 & 53,84 & $* * * * * * * * * * * * * * * * * * * *$ \\
\hline Cocina & Con gas de red & 46,48 & $* * * * * * * * * * * * * * * * *$ \\
\hline
\end{tabular}

FUENTE: elaboración propia sobre la base de la EPH, 2ํㅗ semestre de 2006.

Al respecto, también cabría plantear diversas hipótesis acerca de la inclusión de beneficiarios que pertenecen a la población inactiva. Podría suponerse que en el momento de la incorporación al programa, las beneficiarias integraban la población económicamente activa, o en otras palabras, habían salido de la inactividad. Hay dos efectos que en una situación negativa de alta incertidumbre podrían haberse presentado: "efecto trabajador adicional" ante la necesidad de complementar los ingresos del jefe de hogar o "efecto trabajador alentado" - declarando que buscaba activamente trabajo — ante la alternativa de percibir al menos tres cuartos del SMVM vigente en 2002. 


\section{OBSERVACIONES Y CONCLUSIONES}

El presente estudio describió el contexto socioeconómico reciente de América latina y el Caribe durante la creación de los programas de transferencias directas y algunos debates subyacentes entorno a su implementación. Dichos programas son un instrumento idóneo para reducir la incidencia de la pobreza y de la indigencia porque contribuyen al incrementar el ingreso de los hogares cuya variable es tenida en cuenta para la medición de esos indicadores. Sin embargo, transferir dinero a los hogares no crearía capacidades ni rompería el núcleo duro de la pobreza per se. No mejoraría la alimentación ni la regularidad de los controles de salud. Tampoco garantizaría que ese dinero se oriente a gastos educativos ni sustituya los ingresos del trabajo infantil.

Desde el surgimiento de las transferencias monetarias transcurrió más de una década. Las experiencias regionales muestran la fuerte tendencia a la implementación de esta clase de programas, con similitudes y divergencias. Los pilares centrales de las transferencias directas han introducido innovaciones sociales en materia de cobertura masiva o "cuasiuniversalismo", capacidad institucional, diseño, gestión y evaluación, simplificación de los mecanismos de acceso, generación de espacios de diálogo y participación, focalización en las familias vulnerables y nexo con otras áreas: salud, educación y empleo entre otros.

Algunas experiencias podrían ser consideradas exitosas para mejorar la formulación, la implementación y el monitoreo de estos programas. En algunos casos favorecieron la matriculación y la asistencia escolar, redujeron la incidencia del trabajo infantil y contribuyeron a la reinserción laboral. Aún cabe indagar si esto fue resultado de las condicionalidades propias de los programas y/o de la construcción de redes sociales de contención, orientación y seguimiento de las familias vulnerables, de control de dichas condicionalidades, de la generación de espacios de participación, o de la readaptación de hábitos y estrategias. Al respecto, el debate sobre el rol de las instituciones en la distribución del ingreso y en el diseño de estrategias de largo plazo es fundamental.

En tal sentido, el Oportunidades fue concebido como un programa de largo plazo que permitió abstenerse de los mecanismos de graduación mientras tuvo algunas reformulación, desarrolló evaluaciones permanentes y amplias redes de protección y contención. Sin embargo, el PJH fue concebido como un programa de emergencia con un lapso acotado aunque su vigencia fue prorrogada reiteradamente. Esto nos lleva a observar que el horizonte temporal y la planificación consecuente con él son elementos ineludibles en el diseño de programas y de políticas públicas.

El PJH fue concebido con una perspectiva de derecho universal, por lo cual quien se postulara y cumpliera con los requisitos establecidos, podría obtenerlo. Sin embargo, y pese a su envergadura, la partida presupuestaria destinada a su financiamiento era limitada y requería de mecanismos de focalización adecuados, aunque ante ello habrían operado mecanismos de auto selección en función de la suma otorgada.

Entonces, ¿el gasto público debe implementar esta clase de programas cuasi-universales o masivos y focalizados? ¿debe orientarse a políticas de largo plazo que contribuyan a desarrollar capacidades en todos los estratos de la población? La respuesta demanda jerarquizar necesidades y prioridades con una visión estratégica. 
Los mecanismos de inclusión social a través del empleo no han sido suficientes para distribuir equitativamente el crecimiento fuerte y sostenido posterior a la parálisis productiva a inicios de la década. Los más vulnerables aún permanecen en la pobreza. El programa asumía que el desempleo era una barrera a la inclusión social, e inicialmente reparó en la condición de actividad objetiva del beneficiario, sin considerar la destrucción de capacidades ni la dinámica de la pobreza a la que dicha población había sido expuesta. Aunque el PJH careció de reformulación, en 2004 se implementaron programas sociales complementarios de ingreso que permitieron agudizar la mirada sobre las diversas situaciones de empleabilidad y vulnerabilidad social.

Según encuestas y estudios cualitativos, el PJH tuvo un impacto positivo sobre sus beneficiarios. Sin embargo, no se habría observado un rutina de monitoreo permanente ni un cuestionamiento a los mecanismos de focalización dado el análisis empírico manifestó algunos errores de cobertura y de inclusión. Se advirtió que cerca del 40\% de los beneficiarios no responde a la condición de jefe o jefa de hogar y pertenece a hogares de ingresos medios o altos. Mientras el 56,5\% de este grupo permanece en la inactividad.

Por otro lado, se observó una estrecha vinculación entre la pobreza de ingresos, la vulnerabilidad de los beneficiarios, características socioeconómicas y la inserción laboral en las ramas de actividad de comercio, construcción y servicio doméstico tradicionalmente asociadas con la informalidad y la precariedad laboral. Esto conllevaría a indagar sobre los factores que establecen dicho vínculo.

En términos de consistencia con los objetivos del propio programa, la fiscalización durante la permanencia en el programa hubiera permitido reducir la dimensión del grupo C. De hecho, definir objetivos y cuantificarlos podría haber establecido parámetros ante una evaluación más objetiva. Simultáneamente, cobra importancia la necesidad de establecer un registro único integral de beneficiarios que permita identificar la multiplicidad de beneficios, cruzando múltiples dimensiones para el análisis como ingresos, trabajo, salud, educación y seguridad social que traspasen las jurisdicciones de gobierno.

Los resultados del presente estudio manifiestan que hay una inagotable búsqueda para mejorar el diseño y la implementación de las políticas públicas. Necesariamente, conllevan a profundizar en estudios sobre las estrategias que desarrollan los hogares frente a esta clase de beneficio tanto en materia de percepción e impacto como en la identificación de problemáticas.

\section{Biblografía}

ABRAMO, Lais. Incorporación de la dimensión de género en las políticas de empleo. Experiencias y desafíos. Revista de Trabajo, nueva época, Buenos Aires, n. 1. El empleo en el debate de las Américas, 2005.

ADATO, Michelle; HODDINOTT, John. Condicional cash transfer program. A "magic bullet" for reducing poverty? Washington: IFPRI, 2007.

ALTIMIR, Oscar; BECCARIA, Luis; GONZALEZ ROSADA, Martín. La distribución del ingreso en Argentina, 1974-2000. Revista de la CEPAL, Santiago de Chile, n. 78, 2002. 
BATISTA, J; MARTÍNEZ, M. Análisis multivariante. Barcelona: ESADE, 1989.

BÉCUE, Monica; VALLS i MARSAL, Joan. Manual de introducción a los métodos factoriales y clasificación con SPAD. Servei d'Estadística Universitat Autònoma de Barcelona, 2000.

CETRÁNGOLO, Oscar; JIMENEZ, Juan Pablo. El gasto social y el Programa Jefes y Jefas de Hogar. Buenos Aires, Serie Documentos de Trabajo, OIT, Proyecto Crisis, n. 4, 2003.

COMISIÓN ECONÓMICA para AMÉRICA LATINA y el CARIBE. CEPAL. Estudio económico de América Latina y el Caribe 2007-2008. Santiago de Chile: 2008.

CONTARTESE, Daniel; MACEIRA, Verónica; SCHLESER, Diego. Situación laboral del servicio doméstico en la Argentina. En: Trabajo, ocupación y empleo: relaciones laborales, territorios y grupos particulares de actividad. Serie Estudios/3, Buenos Aires, MTEySS, 2005.

CORNIA, Giovanni Andrea. Coordinación de políticas para la mejora de la distribución del ingreso. Presentación en el seminario Globalización y distribución del ingreso. Problemas y desafíos de políticas. Buenos Aires: MTEySS-OIT-PNUD-CEPAL, 2008.

EVERITT, Brian; DUNN, Graham. Applied multivariate data analysis. Nueva York: Wiley, 1991.

FERNÁNDEZ MACÍAS, Enrique; MUÑOZ, Rafael; ESTEVE, Fernando; GARCÍA, Agustín. Nuevos tiempos de actividad y empleo. Madrid: Ministerio de Trabajo y Asuntos Sociales, 2004.

FOOD AND AGRICULTURE ORGANIZATION. FAO. Panorama del hambre en América Latina y el Caribe 2008: informe preliminar. Santiago de Chile: Observatorio regional de seguridad alimentaria y nutrición, 2008.

GASPARINI, Leonardo; HAIMOVICH, Francisco; OLIVIERI Sergio. Labor informality effects of the Programa Jefes de Hogar. CEDLAS, mimeo, 2006.

GOLBERT, Laura. Argentina: aprendizajes del Programa Jefes y Jefas de Hogar Desocupados. En: ARRIAGADA, Irma. (Coord.). Familias y políticas públicas en América Latina: una historia de desencuentros. Santiago de Chile: CEPAL-UNFPA, 2007.

KOSTZER, Daniel. Argentina: a case study on the Plan Jefes de Hogar Desempleados or the employment road to economic recovery. Mimeo, 2006.

LEBART, Ludovic. Complementary use of correspondence analysis and cluster analysis. En: GREENACRE, Michael; BLASIUS, Jorg. (Eds.). Correspondence analysis in the social sciences. Londres: Academic Press, 1994.

NOVICK, Marta; VILLAFAÑE, Soledad. El trabajo como factor constitutivo de la ciudadanía. En: NOVICK, Marta; PÉREZ SOSTO, Guillermo. (Coord.). El Estado y la reconfiguración de la protección social. Asuntos pendientes. Buenos Aires: Siglo XXI, 2008.

NOYOLA VÁSQUEZ, Juan. Inflación y desarrollo económico en Chile y México en CEPAL (1998). 50 años de pensamiento de la CEPAL. Textos Seleccionados, Santiago de Chile, v. I, FCE-CEPAL, 1957. OCAMPO, José Antonio. Nuestra agenda en La CEPAL en sus 50 años: notas de un seminario conmemorativo, Santiago de Chile: CEPAL, 2000.

RAWLINGS, Laura; RUBIO, Gloria. Evaluating the impact of conditional cash transfer programs: lessons from Latin America. 2003. Disponible en: <http://wwwl.worldbank.org/sp/safetynets/ Conditional\%20Cash\%20Transfer.asp>.

SALVADOR FIGUERAS, Manuel. Análisis de correspondencias. 2003. Disponible en: <http:// www.5campus.com/leccion/correspondencias>.

SORAES, Sergei. La distribución de ingresos y los programas de transferencias: una comparación entre Brasil, Chile y México. IPEA, Brasilia. Presentación en el seminario Globalización y distribución del ingreso. Problemas y desafíos de políticas. Buenos Aires: MTEySS-OIT-PNUD-CEPAL, 2008. 
SUBSECRETARÍA DE PROGRAMACIÓN TÉCNICA Y ESTUDIOS LABORAL. SSPTyEL. Segunda evaluación del PJH: resultados de la encuesta de beneficiarios en trabajo, ocupación y empleo: estudios 2004. Serie estudios/1, Buenos Aires, Métis, 2004.

THERET, Bruno. Crecimiento económico, desigualdad de ingresos e inclusión social: un punto de vista regulacionista. En: NOVICK, Marta; PÉREZ SOSTO, Guillermo. (Coord.). El Estado y la reconfiguración de la protección social. Asuntos pendientes. Buenos Aires: Siglo XXI, 2008.

VERAS SOARES, Fabio; BRITTO, Tatiana. Encarando las limitaciones en la capacidad para TMC en Latinoamérica: los casos de El Salvador y Paraguay. Brasilia: IPC-PNUD, 2008.

VILLATORO, Pablo. Los nuevos programas de protección social asistencial en América Latina y el Caribe. Santiago de Chile: CEPAL, 2008.

WAISGRAIS, Sebastián. Características del empleo asalariado registrado: un análisis multivariante en trabajo, ocupación y empleo: los retos laborales en un proceso de crecimiento sostenido. Serie Estudios/7, Buenos Aires, METySS, 2007.

; SARABIA, Marianela. Heterogeneidad social y productiva: caracterización del trabajo informal en el Gran Buenos Aires. En: BM; MTEySS Aportes a una nueva visión de la informalidad laboral en la Argentina. Buenos Aires: 2008.

Fuentes de información:

www.cepal.org

www.ibge.gov.br

www.imf.org

www.indec.gov.ar

www.inegi.org.mx

www.trabajo.gov.ar

www.worldbank.org 